\title{
System-Level Modeling of an ICE-powered Vehicle with Thermoelectric Waste-Heat-Utilization
}

\author{
Thomas Braig Jörg Ungethüm \\ German Aerospace Center (DLR), Institute of Vehicle Concepts \\ Pfaffenwaldring 38-40, 70569 Stuttgart \\ thomas.braig@dlr.de joerg.ungethuem@dlr.de
}

\begin{abstract}
The reduction of automotive fuel consumption is a major challenge of automotive OEMs and suppliers. It is expected, that during the next decade the majority of vehicles will still be driven by internal combustion engines (ICE). As a rule of thumb about 2/3 of the fuel energy fed to the engine is converted into heat and is used only occasionally and only partly for heating the interior. One promising technology to convert exhaust heat into usable electric energy is the thermoelectric generator (TEG) [1]. As this component has significant retroactive effects on the automotive system, a system-level model of the car was developed to calculate the net benefit of the TEG for steady-state operating-points as well as for dynamic driving cycles.

This paper presents a model and simulation results of an ICE-powered vehicle with thermoelectric wasteheat-utilization. The model uses component models of the AlternativeVehicles-, VehicleInterfaces-, PowerTrain- and YaFluid-Library.

Keywords: waste heat utilization, thermal management, thermoelectric generator
\end{abstract}

\section{Introduction}

A first approach of a TEG-vehicle-model has been presented by Eschenbach et al. on the 5th International Modelica Conference 2006 [3]. Meanwhile several prototypes of thermoelectric generators have been developed at the Institute of Vehicle Concepts which is part of the German Aerospace Center (DLR) (Figure 5).

Simultaneously to this hardware development the AlternativeVehicles-Library has been enlarged and improved. For high level system simulation of thermo-fluid components a new library called YaFluid-Library has been developed.

\section{Model}

At the current stage of development, the TEG prototype is not integrated into the cooling system of the car. Cooling of the TEG is done by a separate cooling cycle with an extra fender mounted cooler. For the prototype phase of development this variant has several advantages:

- reproducible measurements due to minimal thermal interaction between the TEG and other components (especially ICE)

- comparatively simple integration of the TEG into a production car

- simple and flexible control of the coolant flow due to separate coolant pump

In a future stage of development the TEG will be integrated in the common cooling system. This integration variant has following advantages:

- the already existing coolant pump and cooler can be used so that additional weight and aerodynamic drag is avoided

- exhaust heat can be used to shorten the warm-up phase

The aim of the vehicle model is to study the interactions between the TEG and other subsystems and to maximize the energetic net benefit. The TEG is part of the exhaust system but is also connected with the cooling medium as well as with the electric system (Figure 1). Mainly the cooling system and the ICE are affected by the TEG. As shown in Figure 1, ICE and TEG are connected in parallel concerning the cooling agent. The coolant flow through the TEG has to be propelled by the coolant pump and the additional heat flow has to be transferred by the front cooler to the ambient. The TEG can also affect the ICE by an increased exhaust gas back pressure The energetic net benefit of the TEG $P_{n b}$ is the difference between generated electric power $P_{T E G}$ and the sum of the losses due to the TEG $P_{\text {losses }}$. 


$$
\begin{aligned}
& P_{n b}=P_{T E G}-P_{\text {losses }} \\
& P_{\text {losses }}=P_{\text {pump }}+P_{\text {fan }}+P_{\text {backpressure }}
\end{aligned}
$$

$P_{T E G}$ is calculated according equation (5). In case of driving cycles it is more convenient to evaluate work instead of the power.

The backpressure influences the gas-exchange process losses as well as the exhaust residual percentage. Obviously the exhaust pumping work increases with increasing backpressure due to an additional heat exchanger. However, this depends heavily on design and control strategy of the engine. No adequate modeling approach to quantify this retroactive effect has been found in literature, thus this effect is still not considered in the simulation. As the TEG is integrated in the existing cooling system and the front cooler size has not changed, the TEG doesn't cause a higher aerodynamic drag. As the mass of the TEG is low, the influence on the driving resistance can be neglected. During the warm up phase the engine oil temperature is low and therefore the engine friction is high. As the TEG shortens the warm up time it also reduces indirectly the engine loss. This positive effect is still not considered in the model.

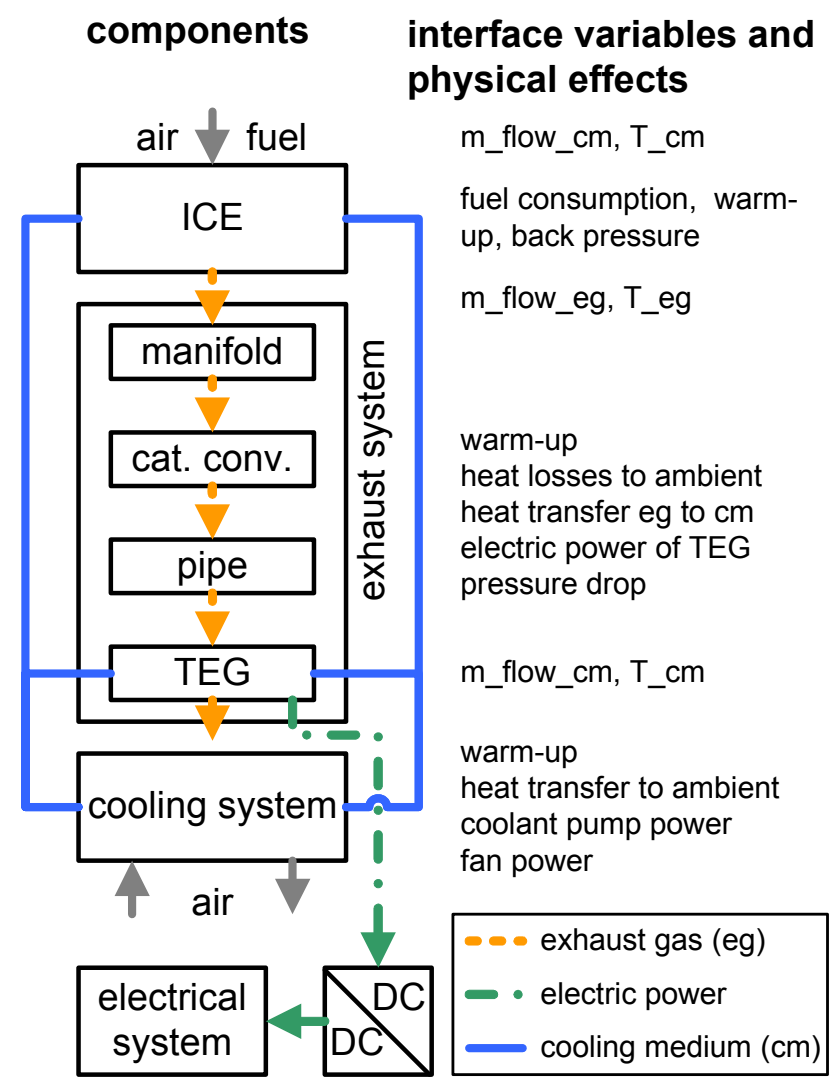

Figure 1 TEG interacting with other components
In the following sub chapters the vehicle, engine, exhaust system and cooling system models will be explained.

\section{$2.1 \quad$ Vehicle model}

The vehicle system model uses components of the AlternativeVehicles-, VehicleInterfaces-, PowerTrain- and YaFluid-Library (Figure 2). The base model is a conventional mid sized vehicle with manual gearshift. The engine model has a fluidPort for the exhaust gas flow and a heatPort for the heat flow into the engineCooling model. EngineCooling, exhaustSystem and coolingSystem are connected by the coolant flow. In one of the spitters (e) the coolant mass flow control system is implemented.

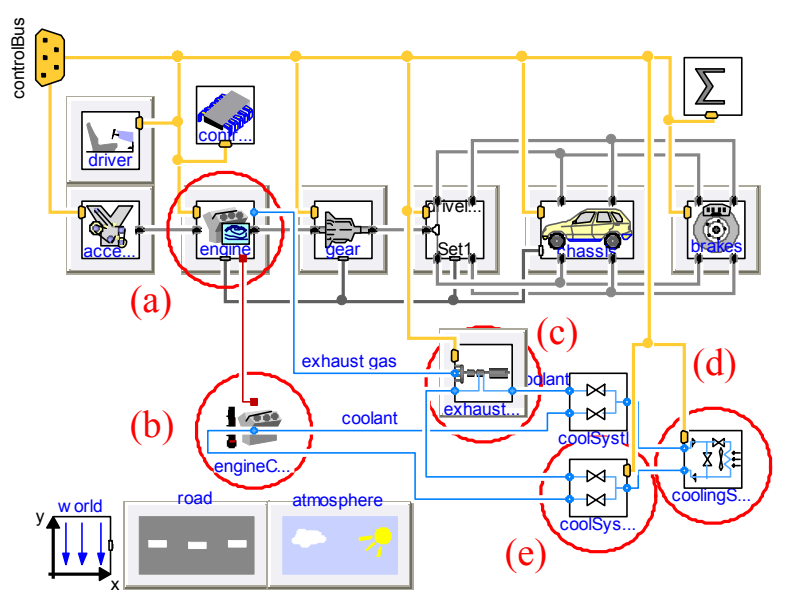

(a) engine, (b) engineCooling, (c) exhaustSystem with TEG, (d) coolingSystem, (e) splitter

\section{Figure 2 Diagram of the vehicle model}

\subsection{Engine model}

The engine model generates the required mechanical power and calculates using a characteristic map also the loss power as well as the fuel consumption.

This loss power $\left(\dot{Q}_{\text {engLoss }}\right)$ is divided into one part that heats the exhaust mass flow $\left(\dot{Q}_{\text {engExh }}\right)$ and another part that warms up the engine block. In the engineCooling model the heat flow $\dot{Q}_{\text {engCooling }}$ which is rejected from the engine block, is calculated. The rejected heat flow consists of the parts ambient heat flow, coolant heat flow and oil heat flow (Figure 3). Each heat transfer coefficient is assumed constant in this model.

$$
\dot{Q}_{\text {engCooling }}=\dot{Q}_{\text {engToAmb }}+\dot{Q}_{\text {engToCoolant }}+\dot{Q}_{\text {engToOil }}
$$


The thermal masses and heat transfer parameters can be determined with engine test benches measurements.

For the calculation of the generated electric power of the TEG, exhaust mass flow and temperature are important input values. The exhaust mass flow is the sum of the fuel flow and the air mass flow. In normal mode the air mass rate can be calculated with the fuel consumption and the lambda value. As at the current state of development only spark-ignition engines are concerned, stoichiometric combustion can be assumed. In the inertia fuel shutoff mode the air mass flow is calculated by the cylinder capacity and the engine speed. The exhaust gas temperature is calculated from its specific enthalpy which in turn is calculated using the mass flow and exhaust loss power $\left(\dot{Q}_{\text {engExh }}\right)$.

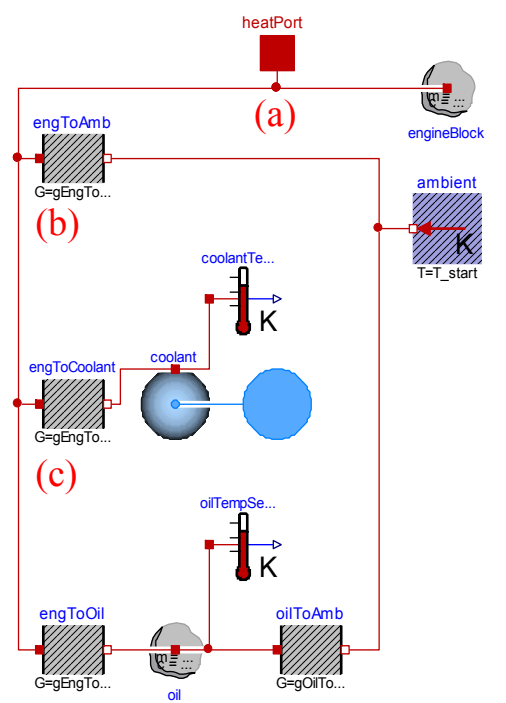

(d)
(a) $\dot{Q}_{\text {engCooling }}$,
(b) $\dot{Q}_{\text {engToAmb }}$,
(d) $\dot{Q}_{\text {engToOil }}$
(c) $\dot{Q}_{\text {engToCoolant }}$,

Figure 3 Diagram oft the EngineCooling model (modified PowerTrain WarmUpModel)

To avoid negative retroactive effects of the TEG due to immoderate increased backpressure, at peak loads the exhaust mass flow is partially bypassed. As the TEG and the engine are coupled by the coolant circuit, the TEG shortens the warm-up phase and reduces the engine friction. In the case that the cooling system gets to its limit, the additional heat flow from the TEG into the coolant might not be passed to ambient and could lead to a further temperature rise of the coolant and engine. In this cases the TEG should also be bypassed.

\subsection{Exhaust system model with TEG}

To ensure that the light-off temperature of the catalytic converter is reached within a reasonable time after cold start, the TEG is mounted in the exhaust system behind the catalytic converter. Any component of conventional exhaust gas systems (manifold, catalytic converter, pipes) does transfer significant amounts of heat to the ambient. These heat losses reduce the exhaust temperature and should be minimized by an adequate isolation if exhaust heat is utilized. In the model the three components are combined to a single valve, a control volume, a thermal mass and the heat transfer to the ambient.

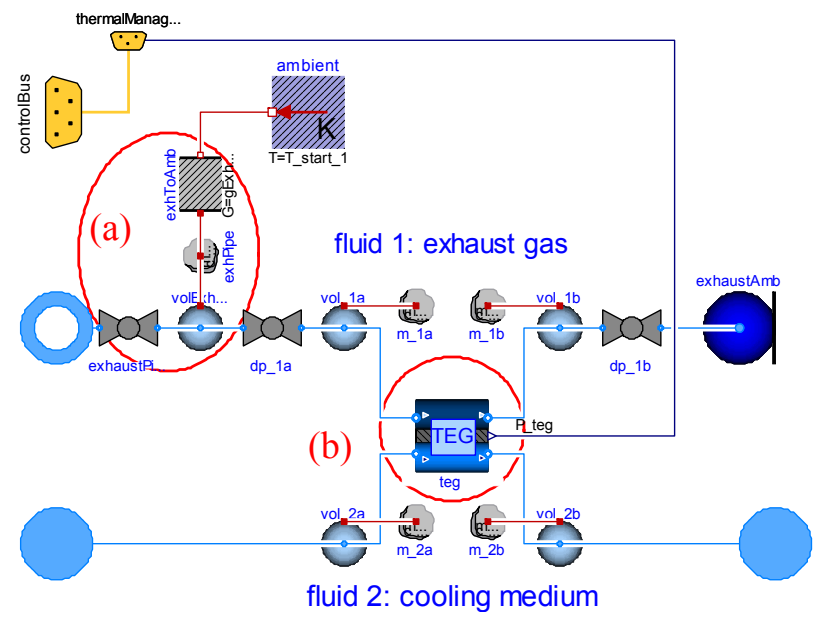

(a) combined manifold, catalytic converter and pipe, (b) TEG

Figure 4 Diagram of the ExhaustSystem model with TEG

\subsection{Thermoelectric Generator (TEG)}

The TEG is a gas-liquid heat exchanger that transfers a heat flow from the hot exhaust gas to the cold coolant (Figure 5). Thermoelectric material (TE) in the wall between the hot and cold sides use the temperature difference to produce an electric potential due to the Seebeck effect. The efficiency of thermoelectric material can be defined as the quotient of the generated electric power and the heat flow at the hot side [2].

$\eta_{T E}=\frac{P_{T E}}{\dot{Q}_{T E}} \rightarrow P_{T E}=\dot{Q}_{T E} \cdot \eta_{T E}$

Not the total wall surface is covered by the thermoelectric material, therefore the factor $c_{T E}$ has to be introduced to calculate the generated power of the TEG. 


$$
\begin{aligned}
& P_{T E G}=\dot{Q}_{T E G} \cdot \eta_{T E} \cdot c_{T E} \\
& \eta_{T E}=\underbrace{\frac{T_{h}-T_{c}}{T_{h}}}_{\eta_{C}} \cdot \frac{1}{Z T}+2-\frac{1}{2} \cdot \frac{T_{h}-T_{c}}{T_{h}}
\end{aligned}
$$

The heat flow $\dot{Q}_{T E G}$ is calculated using the P-NTUMethod [4] and the efficiency of the thermoelectric material $\eta_{T E}$ is interpolated from a lookup table depending on the hot and cold side temperatures. The electric current also affects the efficiency $\eta_{T E}$. However, as a current converter is necessary anyway for the connection to the vehicle electrical system, it is assumed the electric current is forced to an optimum by an appropriate control module. The material data are not available as an equation but as a lookup table. To increase the numeric efficiency the cubic spline approximation provided in the ApproxSpline-Library is used.

As indicated in the equation (6), a large temperature difference between the hot side $T_{h}$ and cold side $T_{c}$ of the thermoelectric material is essential for a reasonable good performance of the TEG. Also the transferred heat flow rises with the temperature difference. The module cold side temperature $T_{c}$ is mainly influenced by the coolant temperature that in turn depends on the engine operation point. The module hot side temperature depends on the exhaust temperature. In general the exhaust temperature rises with the engine load and consequently fast driving cycles with high engine loads are more advantageous for the generated power $P_{T E G}$.

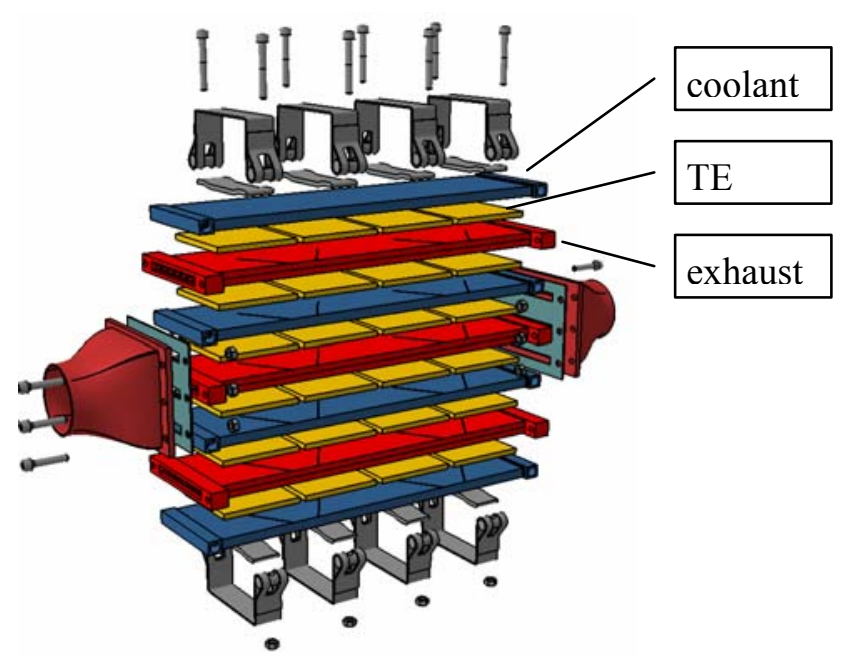

Figure 5 Exploded view of the TEG [2]
For design purposes a detailed discretized model of the TEG is used. For system level simulation it is more convenient to use a concentrated model of the TEG. This model is based on a P-NTU-Method heat exchanger model which is included in the YaFluidLibrary. Several geometries and fin types are available, e.g. louvered fin, wavy fin or offset strip fins. Depending on the geometry several characteristic variables are calculated, e.g. heat transfer areas, Reynolds number, Nusselt number and Fanning friction factor.

Measuring values were available from the Institute of Materials Research which is also part of the German Aerospace Center (DLR). After calibrating the model parameters measurement values and simulation values fit well (Figure 6, Figure 7).

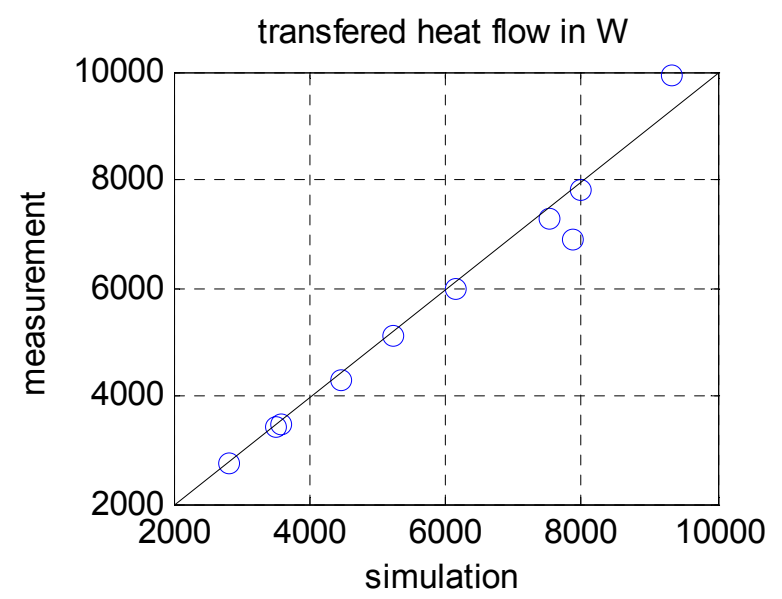

Figure 6 Comparison of simulated and measured transferred heat flow

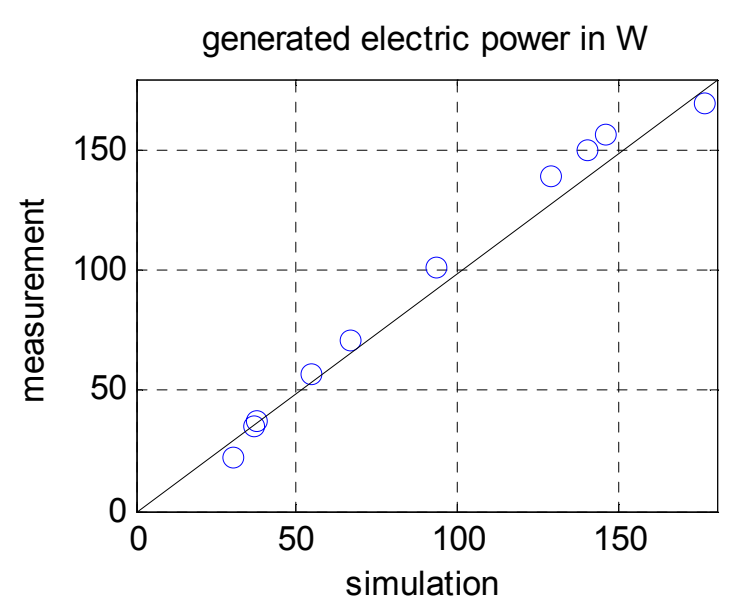

Figure 7 Comparison of simulated and measured generated electric power 


\subsection{Cooling system model}

The amount of heat that the cooling cycle has to transfer to the ambient is given as $\dot{Q}_{\text {engToCoolant }}$. In most cases, the airflow is sufficient to reject the heat from the coolant. Only at low vehicle speed additional energy effort is necessary to force air through the front cooler by a fan. The TEG causes an additional heat flow $\dot{Q}_{T E G}$ into the cooling cycle, which is calculated in the TEG model as mentioned above.

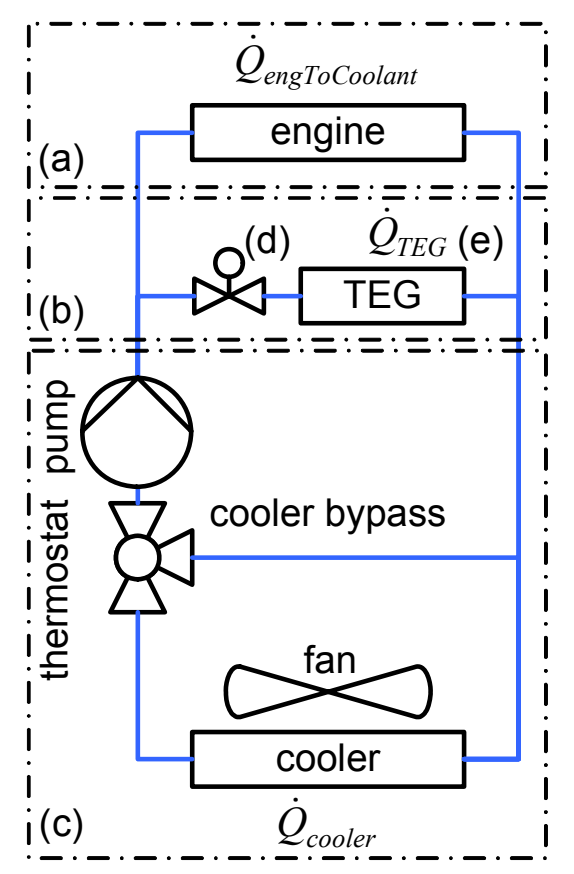

(a) engineCooling, (b) exhaustSystem, (c) coolingSystem, (d) controlled valve, (e) TEG coolant outlet

\section{Figure 8 Simplified cooling circuit}

After cold start the operating temperature of the engine should be reached as fast as possible. Therefore the bypass is fully opened and almost no coolant runs through the cooler. Between the coolant temperatures $T_{\text {lower }}$ and $T_{\text {upper }}$ the bypass is gradually closed. If the coolant temperature exeeds the upper temperature limit, the bypass is fully closed. Up to a certain velocity $\left(v_{\text {FanOn }}\right)$ the heat transfer to ambient can be improved by switching on the fan.

In the cooling system model the heat flow $\dot{Q}_{\text {cooler }}$ from coolant to ambient is calculated (Figure 10). Therefore the simple approach

$$
\dot{Q}_{\text {cooler }}=G_{\text {cooler }} \cdot \Delta T_{\text {cooler }}=G_{\text {cooler }}\left(T_{\text {coolant }}-T_{\text {amb }}\right)
$$

is used, where $T_{\text {coolant }}$ is the coolant temperature, $T_{a m b}$ is the air temperature of the ambient and $G_{\text {cooler }}$ is the thermal conductance (product of the heat trans- fer coefficient and heat transfer area). $G_{\text {cooler }}$ depends primarily on the geometry and furthermore on mass flows of air and coolant.

At engine peak load $G_{\text {cooler }}$ has to be sufficient to reject the engine waste heat $\dot{Q}_{\text {engToCoolant }}$ to the ambient. The driving resistance of a given vehicle varies with slope and payload. Thus, the lowest vehicle speed at which maximum engine load is achievable is defined by the cooler design. Figure 9 shows a simple cooler design procedure. A simulation of the engine waste heat flow rate in dependence of vehicle speed at zero gradient which covers the complete power range of the engine is done. To ascertain an adequate thermal conduction of the cooler, the following assumptions were made:

- coolant mass flow and temperature are constant

- $\dot{Q}_{\text {engToAmb }}$ and $\dot{Q}_{\text {engToOil }}$ are neglected, thus $\dot{Q}_{\text {engToCoolant }}=\dot{Q}_{\text {engCooling }}$

- the air velocity through the cooler is equal to the car velocity

Thus, $G_{\text {cooler }}$ depends only on the cooler air flow which is directly linked to the car velocity. At maximum vehicle speed the cooler has to transfer the maximum engine waste heat (Figure 9 point (a)).

$\dot{Q}_{\text {cooler }}\left(v_{\max }\right)=\dot{Q}_{\text {engToCoolant }}\left(v_{\max }\right)$

As a worst-case approximation, it is assumed the thermal conductance depends linear on the vehicle velocity (line (d) in Figure 9). Cooler maps show, that this underestimates the actual thermal conductance of real world coolers (the characteristic curve (c) promises a higher heat transfer than the linear approach (d) delivers).

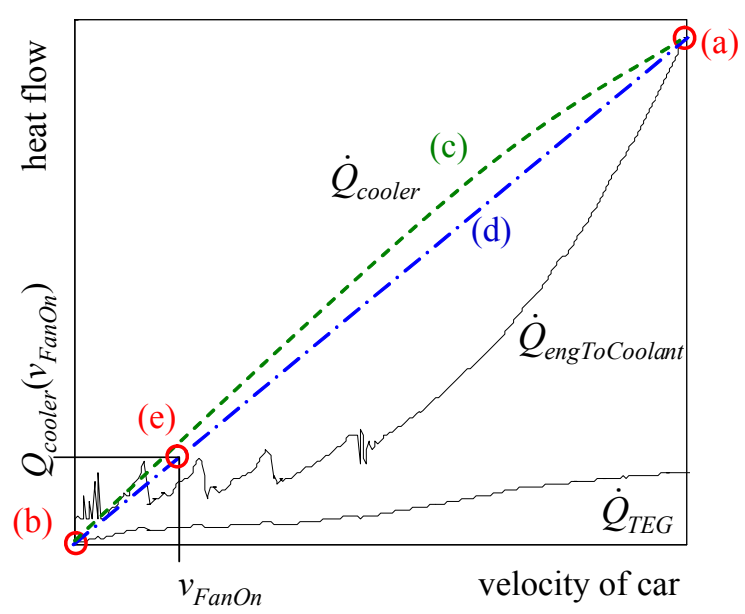

Figure 9 Identification of $\boldsymbol{Q}_{\text {cooler }}$ respective $\boldsymbol{G}_{\text {cooler }}$ 
Thus, the cooler conductance is calculated as follows.

$$
\begin{aligned}
& G_{\text {cooler }, v}(v=0)=0 \\
& G_{\text {cooler }, v}\left(v=v_{\max }\right)=\dot{Q}_{\text {engToCoolant }}\left(v_{\max }\right) / \Delta T_{\text {cooler }} \\
& G_{\text {cooler }, v}(v)=v \cdot G_{\text {cooler }, v}\left(v_{\max }\right) / v_{\max }
\end{aligned}
$$

As a consequence of the linear approach, the heat rejection of the cooler is insufficient at low vehicle speed. This leads to a continuously rising coolant temperature up to a certain temperature $T_{\text {fanon }}$ where the fan is switched on and forces the airflow through the cooler with the velocity $v_{\text {fanOn }}$.

$$
\begin{aligned}
& G_{\text {cooler }, \text { fan }}=G_{\text {cooler }, v}\left(v=v_{\text {FanOn } n}\right) \\
& G_{\text {cooler }}(v)=\left\{\begin{array}{r}
T_{\text {coolant }}>T_{\text {FanOn }}: G_{\text {cooler, fan }} \\
\text { else }: G_{\text {cooler }, v}(v)
\end{array}\right.
\end{aligned}
$$

The heat rejection is implemented in the cooler model (Figure 10).

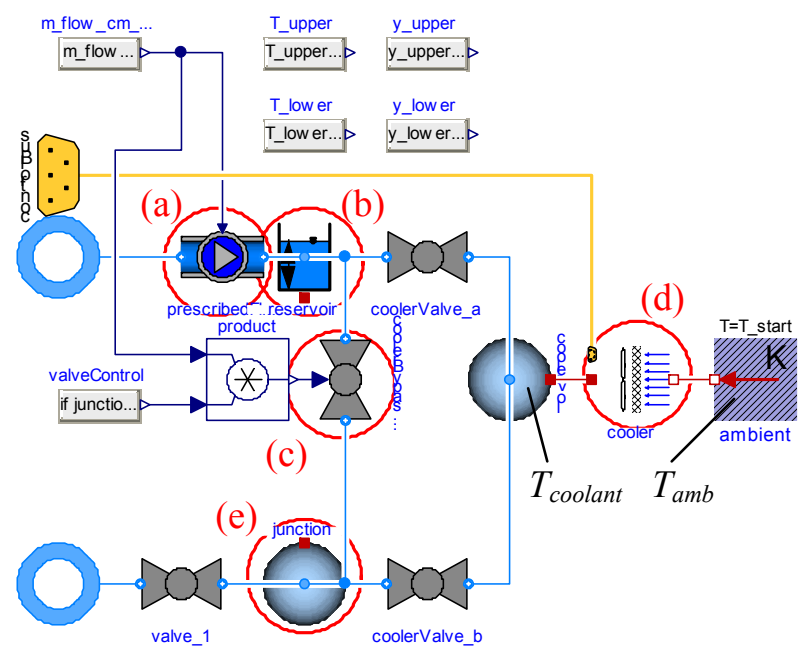

(a) pump, (b) reservoir, (c) bypass valve, (d) cooler, (e) junction

\section{Figure 10 Diagram of the CoolingSystem model}

As indicated at Figure 8 the coolant flow through the bypass depends on the coolant temperature (Figure 10 (e)) and the temperature limits $T_{\text {lower }}$ and $T_{\text {upper }}$.

The coolant flow through the TEG has to be forced by the coolant pump and consequently this pumping power is considered in the energetic net benefit (eq. (1)). It is the product of volume flow and pressure loss divided by pump efficiency. The pressure loss is calculated using a fitting curve on the base of measurement values. Only the pressure loss of the TEG is considered, not the pressure loss of the control valve. The latter is determined by the pressure loss of the engine, as the total pressure differences of both parallel passes are equal. To minimize the pumping power the coolant mass flow is controlled depending on the difference of coolant outlet temperature of the TEG (Figure 8 (d), (e)) and the coolant outlet temperature at design point (set point).

\section{Simulation}

For the simulation model a mid sized vehicle with an $85 \mathrm{~kW}$ powered gasoline engine was used (Table 1). Whether the energetic net benefit of the TEG is positive or not depends crucially on the concrete driving cycle and the TEG efficiency. The TEG used here is designed for waste heat recovery at medium to high engine load. Thus, a suitably driving cycle must be used to achieve reasonable results. In general the Artemis Driving Cycles show a much more realistic daily life driving behaviors than the often used New European Driving Cycle (NEDC) [6]. Considering the TEG design, the Artemis motorway driving cycle is an adequate driving cycle for this study (Figure 11).

Table 1 Parameters of the vehicle model

\begin{tabular}{|l|l|}
\hline Parameter & Value \\
\hline Vehicle mass (2/3 load) & $1575 \mathrm{~kg}$ \\
\hline Engine power & $85 \mathrm{~kW}$ at $60001 / \mathrm{min}$ \\
\hline Engine displacement & 1.61 \\
\hline Engine max. torque & $155 \mathrm{Nm}$ at $40001 / \mathrm{min}$ \\
\hline TEG 1 & $\begin{array}{l}\text { bismuth telluride } \\
\left(\mathrm{Bi}_{2} \mathrm{Te}_{3}\right)\end{array}$ \\
\hline TEG 2 & lead telluride $(\mathrm{PbTe})$ \\
\hline
\end{tabular}

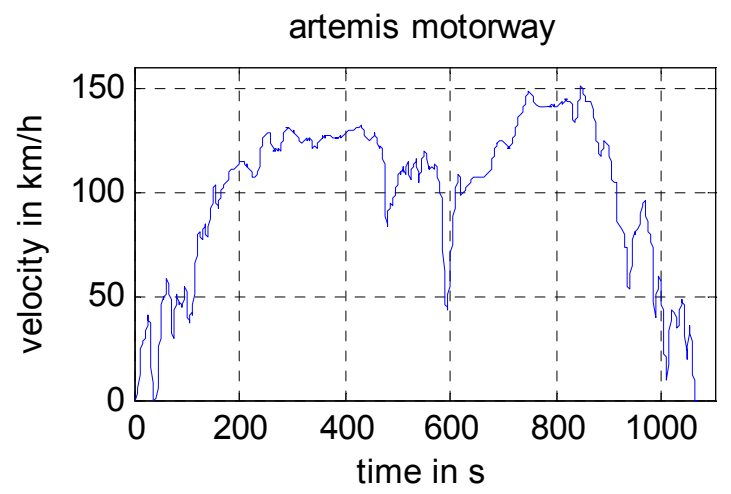

Figure 11 Velocity in the artemis motorway driving cycle 
Two variants of a TEG are simulated, first a state of the art TEG with the thermoelectric material bismuth telluride $\left(\mathrm{Bi}_{2} \mathrm{Te}_{3}\right)$ (TEG 1) and second an improved TEG with lead telluride (PbTe) and an enhanced heat transfer characteristic (TEG 2).

For both TEG variants the power according eq. (1) has been calculated and plotted. The generated electric power of the TEG has been calculated in dependency on fluid mass flow rates and temperatures as well as the geometry of the TEG. Due to the high vehicle velocity in the Artemis motorway cycle and consequently high heat transfer to ambient the front cooler fan is never switched on. In this simulation the power loss of eq. (2) is equal to the coolant pumping power.

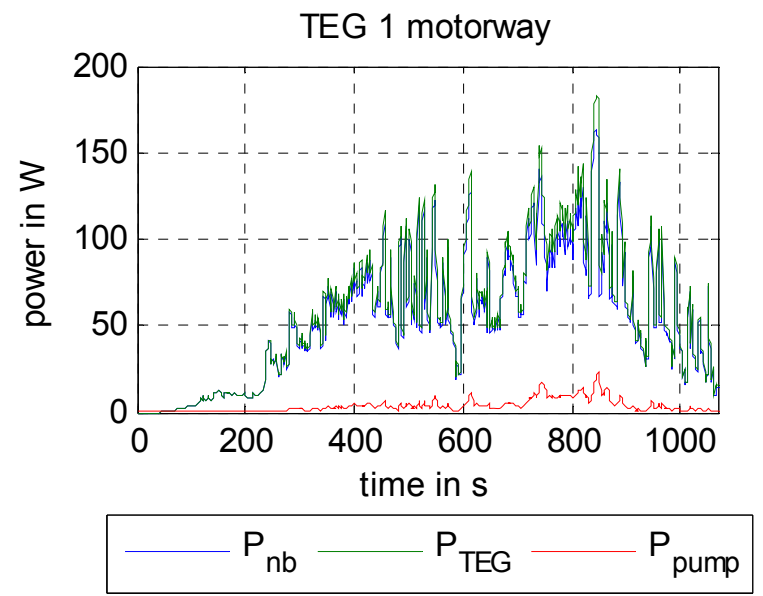

Figure 12 TEG 1 motorway: powers

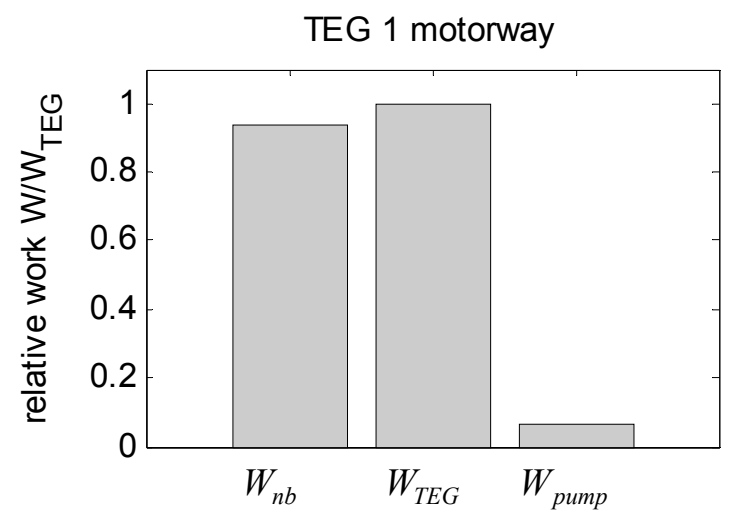

Figure 13 TEG 1 motorway: works

At simulation start the temperature difference between the hot and cold side of the TEG is zero, thus the heat transfer and the generated electric power are also zero. As the thermal mass of the coolant and exhaust system warm up, the temperature difference across the thermoelectric module and the generated electric power rises.
Due to the effective control of the coolant mass flow rate the pumping power is kept quite small in comparison to the generated electric power (Figure 12 and Figure 13). During the warm up time the coolant temperature is still low. Consequently the coolant mass flow as well as the pumping power are minimal.

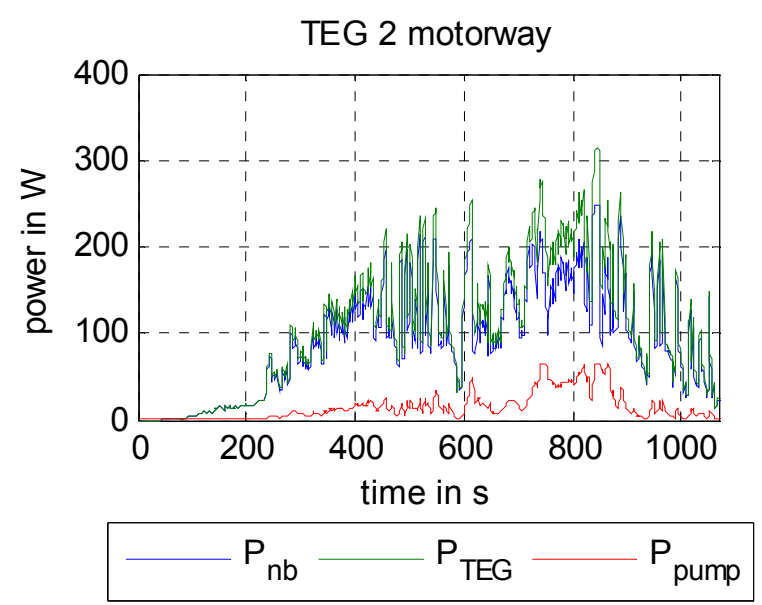

Figure 14 TEG 2 motorway: powers

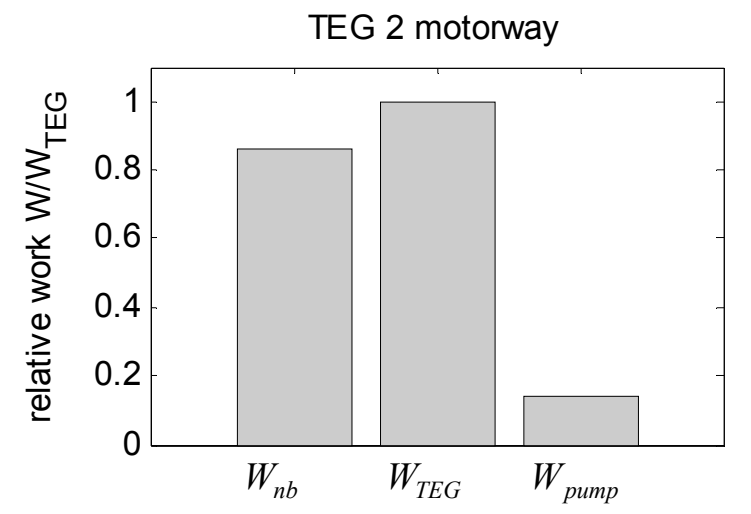

Figure 15 TEG 2 motorway: works

Thanks to the higher operation temperature of the thermoelectric material lead telluride $(\mathrm{PbTe})$ and the enhanced heat transfer characteristic the TEG 2 generates up to $310 \mathrm{~W}$ electric power. In comparison to the TEG 1 the net benefit work is about $70 \%$ higher. Due to the higher transferred heat flow the warm up time is even more reduced. The higher heat flow leads also to a higher coolant mass flow through the TEG and consequently the pumping work rises. As the pumping power rises quadratically, also the pumping work increases disproportionately to the generated electric energy. 


\section{Conclusions}

A mid sized car equipped with a thermoelectric generator (TEG) for exhaust heat recovery has been modeled based on the Modelica libraries AlternativeVehicles, VehicleInterfaces, PowerTrain, ApproxSpline and YaFluid. The mutual interferences of the components have been studied and on the basis of two TEG variants the potential augmentation of the generated net benefit power as well as the net benefit work have been analyzed. However using commercially available thermoelectric modules $\left(\mathrm{Bi}_{2} \mathrm{Te}_{3}\right)$ the TEG reaches values up to $180 \mathrm{~W}, 310$ $\mathrm{W}$ are obtainable using lead telluride $(\mathrm{PbTe})$. Improved thermoelectric materials, control of coolant and exhaust flow as well as possible reductions of the exhaust and coolant pressure losses have a significant potential to improve the energetic net benefit of TEG equipped cars in future.

For the calculation of the net benefit of waste-heatutilization-technologies it is important not just to focus on single components but to examine the entire system. The AlternativeVehicles-library is suitable to model various vehicle concepts and enables understanding and optimizing the whole vehicle system.

\section{References}

[1] Friedrich, Treffinger, Müller: Management von Sekundärenergie und Energiewandlung von Verlustwärmeströmen. ATZ/MTZKonferenz - Energie, München, 2007

[2] Treffinger, Häfele, Weiler, Eder, Richter, Mazar: Energierückgewinnung durch Wandlung von Abwärme in Nutzenergie (Recovery of energy through conversion of waste heat), Innovative Fahrzeugantriebe, Dresden, 2008

[3] Eschenbach, Ungethüm, Treffinger: Vehicle model for transient simulation of a wasteheat-utilisation-unit containing extended PowerTrain and Fluid library components, 5th International Modelica Conference, Vienna, 2006

[4] Shah, Sekulic: Fundamentals of Heat Exchanger Design, John Wiley and Sons, Hoboken, 2003

[5] Ungethüm, Hülsebusch: Implementation of a Modelica Library for Smooth Spline Approximation, 7th International Modelica Conference, Como, 2009

[6] M. André: Real-world Driving Cycles for Measuring Cars Pollutant Emissions. Part A:
The Artemis European Driving Cycle. Institut National de Recherche surles Transports et leur Securité (INRETS), Bron, 2004 